\title{
Operational autonomy explains the value of group work in both lean and reflective production
}

\author{
Roel W. Schuring
}

School of M anagement Studies, University of T wente, The N etherlands

\section{Introduction}

Group work is one of the main features of lean production. A mong others, Womack et al.[1] and A dler and Cole[2] refer to teams or work groups as an important ingredient of lean production. But in other approaches also, use is made of teams. It is the core element of the sociotechnical approach, which is instrumental to what is sometimes refer red to as "reflective production"[3]. A recent survey carried out in The Netherlands in medium and large industrial companies showed that 51 per cent of blue-collar workers and 46 per cent of white-collar workers are employed in teams which do their own planning, inspection, etc. But group work is not all the same. A dler and Cole[2] and Berggren[4] are the exponents of the discussion that takes place about the differences between the design of lean and reflective production sites. The role of group work is an important element in the debate. Benders and de Leede[5] emphasize that work groups within the lean production concept are based on the use of standard operating procedures (SOPs) and have a clear hierarchy with close supervision, while the work groups based on a sociotechnical design have a certain degree of autonomy in the choice of work methods. Successful examples can be given of both kinds of group. Is it possible to explain why such different approaches in work group design lead to success?

To answer this question, two cases were selected from a larger set based on the fact that they represented the two above-mentioned extreme designs of work group. Other cases in our study used a less pronounced concept. In retrospect, our conclusions regarding the extremes also seem to apply to these cases. The approach is in line with Y in's case study approach[6], which asks for different cases in order to permit "theoretical generalization".

The reflective production case is a Swedish assembly site of passenger cars. The data for this case were collected in 1990 and reviewed and reconsidered in 1995 with the co-operation of company officials. The second case represents group work in a lean facility. It is a distribution centre for a Japanese car

With regard to the preparation of the lean production case study, the author wishes specially to acknow ledge the kind support of J. de Brouwer. 
IJOPM 16,2

172

manufacturer in Europe. In this facility spare parts are collected and cars are prepared for despatch to dealers. This case was studied in 1994. The words "lean" and "reflective" describe both the author's classification of the two cases and the classification which company representatives themselves gave of their own company. Both cases were perceived as extremely successful by their representatives. The reflective production case will be discussed in the next section. Thelean production case will be discussed in the third section. It will be concluded in the final section that both approaches to teamwork lead to "operational autonomy".

Operational autonomy refers to a situation in which the operational processes run autonomously. So, there is no need for online intervention, assistance or direct control of operators by the rest of the organization. No involvement is needed during the actual operational process by planning departments, quality inspectors, supervisors, managers or managers from other parts of the operational chain, etc. In a situation without operational autonomy there are many people within the organization, who all have a small stake in the execution or preparation of the operational process part of the regular working procedure. So frequent consultation and interruption of staff departments and supervisors by the operators is necessary and vice versa. Operational autonomy is a desirable situation. It increases the transparency of the operational process of the organization. Also, fewer indirect staff members are needed, as a lot of communication, thinking, pre-thinking and re-thinking is simply avoided or done already. Local control improves the degree of utilization of resources and the labour productivity on operational level and it reduces balancing losses. Short feedback cycles result in a reduction of inventories and a better lead time and process reliability.

To achieve "operational autonomy" asks for efforts in the design of the operational process. Both reflective and lean production provide such an approach. Both approaches will result in a reduction of the complexity of the organization.

\section{Reflective production: the fundament and a case}

The fundament

There is a long history relating to the science of work group design. Theorizing has gradually taken place since the original article by Trist and Bamforth on alternative organizational forms of mining in 1951[7]. Many of the sociotechnical ideas find their origins in the Tavistock Institute for Human Relations, such as Herbst's[8] view that clear physical boundaries of groups support group work. Often, the views are prescriptive, like an overview provided by Cherns[9] who gives a list: "for those involved in design, it is both an aim and a checklist". T his list is a renewed version of a list dating from 1976. In an overview by De Sitter et al.[10] there is a focus on the relevance of interactions between groups. Such interactions may militate against the possibility of having own-task policies within the group. Checklists in the Dutch sociotechnical stream of thought by Kuipers[11] and by Kuipers and van 
A melsvoort[12], contain many elements from Cherns' list, but are more comprehensive. They stress that the leading principle should be that the work group is seen as the largest entity that can function without any division (the principle of minimal differentiation). Within the work groups the design should be guided by the four principles of self-organization that were gathered by Morgan[13] in the "brain metaphor". The principle of "redundancy of functions"[14] means that each group member can engage in a range of autonomy functions rather than just perform a single specialized activity. This leads to an organizational design that possesses flexibility and capacity for reorganization within each part of the system. "Requisite variety"[15] means that the internal diversity of the group matches the variety and complexity of challenges presented by the group's environment. Furthermore, "minimal critical specification"[16] requires that no more should be specified than is absolutely essential. Finally, "double loop learning"[17] means that the group is not only able to detect and correct errors in relation to a given set of operating norms but should also be able to question their relevance. Moreover, Kuipers sums up state-of-the art guidelines for group tasks, borders of tasks, group interaction, rewards, and group size and the link between technical systems and the concept of group-work. Van Eijnatten[18] studied over 2,500 articles in the field of sociotechnics. His conclusion is that the foundations of all approaches within the sociotechnique concern participation and democracy in the workplace. Rules for the design of work groups share such elements as: minimizing labour division, internal co-ordination and control, minimal critical specification, group-based organization instead of individual-based organization, multiskilled personnel, active learning and accepting responsibilities.

The sociotechnical approach simultaneously wants to create attractive jobs for workers and an attractive production process for the company. If we concentrate on the latter, we notice this is done by establishing: clearly delineated, coherent (or semi-autonomous) work groups that are capable performers of operational processes which under all normally occurring circumstances, take place in line with the requirements of the organization:

- Clearly delineated, coherent, work groups. The work groups are the building blocks of the organization. The concept is that there is a strong coherence within the building blocks. At the same time the building blocks can function as independently from one another as possible.

The coherence within the group will be improved by mutual dependence in the execution of operational tasks within the group. A Iso, task rotation and limited division of tasks will improve coherence and mutual understanding of group members. Coherence-subverting processes should be controlled. In practice this means that nonproductive differences in status or remuneration should be prevented and the group should learn to manage in-group conflicts and to cope with less-skilled group members. A clear delineation of the group can be achieved by keeping it small enough to enable communication between 
IJOPM

16,2

174 members and by allocating a clearly marked area to the group. A Iso, logistical or other streams between groups should be reduced to an absolute minimum. A dditionally, conflicts between groups should be prevented or managed. Finally, groups should be supported by productoriented staff departments rather than functional departments as these may lack orientation towards operational processes.

- Work groups as capable performers of operational processes. Independence and group cohesion are of no value if the group is not capable of performing a set of operational tasks. A $n$ industrial situation such a set of tasks will normally include planning aspects, quality aspects, materials handling and maintenance activities. The idea is that the work groups do not need support from others to do their work. A lso, no further quality control or other checks by others should be needed, as this would be against the idea of using the groups as organizational building blocks.

Only minimal critical specifications are given to enable the group to build up their own working procedures. Redundancy of functions and requisite variety are needed to cover all tasks in all situations. Practically, people's skills regarding operational, maintenance, control, inspection and other tasks are important. So, people should be trained and be rewarded for attending training or mastering skills. Furthermore, all the required information and means should be provided to perform the necessary tasks under all circumstances.

- Operational processes in line with the requirements of the organization. The work groups have considerable autonomy, but their task policy should still be in line with the requirements of the organization. This is a delicate problem, as independence of groups seems to conflict with the necessity to take decisions in line with the policy of the organization. The philosophy within the sociotechnical approach is that only a large degree of independence allows the required decision making of the group. Groups are given the capability, the authority, the information and the time to take such decisions; only minimal critical specification takes place by the organization. The capability to take the right operational decisions depends on decision-making and creative skills and instruments, and on understanding the functioning of the group within the entire organization. The acceptance of responsibilities by the work group should secure the fit between their decisions and the organization's policy. A central element is the required double look. This means that the group should not only be capable of improving their current processes and make the right decisions regarding these processes, they should also be able to challenge the current processes and be willing to replace them for entirely new working methods. A risk of the sociotechnical solution is the possibility of group-think[19].

A II in all, operational autonomy is achieved through decentralized problem solving in autonomous groups. 
The case

A s indicated in the introduction, two cases were selected from a larger set because they represented reflective and lean production respectively. Case 1 is a Swedish passenger car assembly plant. The data for this case were collected in 1990. Managers were interviewed who were (co-)responsible for the design of the organization. The collected data were reviewed and reconsidered in 1992 and 1995 on the basis of further contacts with people who were involved in the original design process.

A $n$ aim during the design of this organization was to create a facility which was attractive to work in, as low unemployment figures at the time of the design made it difficult to find people who wanted to work in industry. The implicit assumption was that a high autonomy of work makes work attractive. The work groups were visited during working hours, but no group members were interviewed.

In total, about 800 people worked in this factory. The organization was entirely composed of autonomous work groups. There were five separate assembly units, each consisting of seven work groups with eight to ten persons. A II the assembly work groups were served logistically by a central warehouse in which other work groups prepared kits. The collection of the parts for four kits per car took about one-third of the total direct-labour hours in this factory. Furthermore, two separate groups did all testing and adjustment work. They made use of specialized equipment which was not available to the assembly groups. A lthough the warehouse groups, the assembly groups and the test groups worked sequentially, there were clear decoupling points to make the groups as autonomous as possible.

The assembly groups assembled two, three or four cars daily, depending on the size of the group, the experience and skill of the group members and on the exact specifications of the car. T here were about 2,700 parts per car to be fixed. Ergonomically designed tools were provided, also for tilting and turning the cars. Each group worked simultaneously on three or four cars, which meant that betw een two and three people worked on each car at a time. The work-cycle was between two and three hours. Formally recognized skills were divided into seven sets of tasks. Each employee had to master at least three of these sets. There was a separate workshop where the most skilled employees were instructed. They occasionally assisted in the development of new working procedures. These skilled employees, in turn, taught their fellow group members. It took about three months to educate fresh employees to a reasonable level. Berggren[4], who studied the same case, emphasizes that training was directed towards the understanding of the links between various parts. The reflective principle refers to skill formation as an integration of mental maps and manual skills, which is different from traditional job enlargement. A lthough the group was based on the reflective principle and although groups had a certain autonomy, it should be stressed that the distribution and balancing of activities were also subject to centrally discussed schemes. These schemes were influenced by the strong interactions between product engineers and the 
IJOPM 16,2

176

assembly teams. The way in which the parts were provided in the kits played a crucial role in this respect, as they reflected centrally considered assembly procedures. The structuring of the kits was equal for all groups which limited the group autonomy to change procedures. Every team had a spokesperson function. This was a rotating function among those who were qualified to do this job. The spokesperson set the pace in the group, assigned tasks to group members and took care of planning aspects. Also, he or she had to lead the discussion about improvements within the team.

The reward system was linked to what management considered to be critical. A t first, bonuses were given for mastering more than one of the seven sets of skills. A bove a minimum quality-level a bonus was given to the members of the group based on quality (50 per cent), man hours (30 per cent) and delivery accuracy (20 per cent). A lso, there was a bonus for those who participated in the rotating spokesperson function.

There were separate canteens for every two groups, where a monitor displayed the actual production results of the entire factory. Each group consisted of a mix of female and male, young and old, experienced and lessexperienced workers. In the case of conflicts between employees, someone could shift to another team. Group pressure made people feel responsible and also, occasionally, people felt forced to do more work than they were actually capable of doing. This was a source of mental and physical problems. It is still a question as to whether the initial pre-assumption that a higher autonomy leads to more attractive work is correct, as the turnover figures and absenteeism (11 to 12 per cent in 1990, gradually falling to the level of other Volvo factories) were not outstanding in comparison with other factories.

The factory was closed down some two-and-a-half years after this study for reasons which are not directly related to its performance. Just before the closure, a relevant change was made in the composition of the management team of the facility. A t first, there was a management team in which functional staff departments had a representative. Later there was a management team in which the various workshops in which the workgroups operated were represented. In retrospect, the people who were involved in the design of the factory regard the latter situation as preferable to the initial situation. Currently (June 1995) the factory is in a restart process, in which the design of the groups and the organization around the groups will be similar to that just before the closure.

A nalysis shows that the establishment of clearly delineated coherent work groups is supported through a number of design characteristics. The various tasks within the group are clearly interrelated and the multi-skilled operators can understand one another's tasks. The logistical control system allows each group to work relatively independently of the remainder of the organization. The bonus system is partially based on group performance, which supports feelings of coherence in the group. The information system allows the group to work independently of staff-departments. The groups are small enough for communication within them. The entire organization is built up using groups. 
A Iso, in a later stage, the structure of central management reflected this, even though central management has stressed the importance of groups in earlier stages too. The capability of performing operational tasks is ensured through the education of multi-skilled personnel and through dedicated tools. A Iso, group pressure leads individuals to higher standards of working, although this was not instrumental in the design of the organization. A number of measures are taken to assure that operational processes take place in line with the requirements of the organization. First, the central training centre supports the fit between decision making in the groups and the requirements of the organization. Second, organizational goals, such as quality, delivery reliability and cost reduction are clearly targeted in the bonus scheme.

It may be concluded that a situation of operational autonomy was finally achieved.

\section{Lean production}

The fundament

The term "Iean production" was first introduced by Womack et al. in The $M$ achine that Changed the World[1]. So, this approach is of more recent date than the sociotechnical one. In many publications which have appeared since, it gradually became clearer what lean production is. The original authors proposed a next step called "the lean enterprise"[20]. However, the focus of the current publication is on the production process. If we take this point of view, what are the core design characteristics of lean production?

The customer focus is dominant in all activities in the company. Throughout the organization, it is made clear for employees what the link is between their own role and what is relevant for the customer. Next, the process focus is essential. Processes are no longer split up functionally, but linked in a flow. If consultation of others is necessary, this is done online. However, this should normally not be necessary, as support staff are as decentralized as possible. A Iso, it is strongly linked to the operational process. Disturbances in the operational process are prevented, for example by a planning system that smooths the demand. Finally, kaizen or continuous improvement is an essential element. Continuous improvement means that there is a permanent search for the elimination and modification of tasks for further alignment of processes to one another and to various situations that may occur in an ever more effective way. Learning takes place by installing ever better standard operational procedures. Unnecessary process steps are eliminated. Unnecessary inventories are eliminated. Solutions for problems are implemented at the source.

Teams are an important element of lean production. In production, teams are held responsible for the correct execution of the standardized tasks in the process. Team members should help one another and notice others' mistakes. They should immediately report when there are any problems. However, no ad hoc course of action should be chosen. New procedures need to be installed in such instances. 
IJOPM 16,2

178
The case

The "lean" case was studied in 1994. It is a European distribution centre for a Japanese car manufacturer, from where spare parts and cars are distributed to various countries in Europe.

In the car distribution centre, about 1,000 cars are prepared for distribution on a mechanically paced line from a central stock. First, wax is removed automatically, remaining drops of water are dried manually, inspection regarding full removal of wax, possible damage and correct locking of bonnet and doors takes place. A country-specific car manual is added and instructive stickers are attached, for example, concerning tyre pressure. A fter 58 seconds the car is normally ready for shipment. However, damage and unremoved wax are taken care of and sometimes accessories such as light-alloy wheels need to be fitted. Twenty per cent of the cars are inspected for a second time and data from this second inspection are fed back for further improvement of existing operations.

In the parts distribution centre, some 100,000 different parts are stocked. A bout 4,000 car dealers in European countries are supplied from this stock through importers, while the national dealers are supplied directly. This distribution centre is a highly automated facility. Order picking of smaller parts is semi-automated, while picking of larger parts is fully automated.

All employees in both facilities work in teams. These groups have only limited freedom in the execution of operational tasks as even the smallest task is prescribed in a standard operational procedure (SOP). Fifteen people work in a team. There are two "key people" and there is one supervisor. A supervisor reinforces the correct execution of the SOPs within a strong hierarchy. He/she does not literally monitor this as he/she is not present continuously. In case of sick-leave, the work group is asked to put in some extra effort. A lso the employees have flexible working hours which depend on demand. Job-rotation is important in both sites. There is dedicated training for every task. The achieved skills, which vary from A (apprentice) to $F$ (trainer), are displayed on posters in each work place. Mastering a task on level $\mathrm{F}$ means that one is allowed to change that task's SOP. There are specialist-groups for repair and assembly. Education clearly is regarded as important and the aim is the multiskilling of employees.

Involvement in the improvement of activities of employees is on the one hand considered to be a natural part of everyone's job. On the other hand, the involvement in improvement is normally restricted to reporting problems to the supervisor. The supervisor has to decide how to change the SOP. If there were no SOPs, this kind of improvement would not be possible. Each group should deliver at least one problem monthly although there is no suggestion box. If an employee has a proposal to change a SOP, he/she should discuss this with his/her supervisor on a voluntary basis. There is no immediate reward for involvement in improvement suggestions. However, the improvement suggestions of employees are a basis for bonuses and are a factor in the 
assessment of the employee, as improvement suggestions are considered to be a measure of the employee's loyalty and dedication.

Instead of "bothering the work groups with the strategy of the company", as one representative called it, clear goals are communicated intensively to "set the mind of the employees". The same slogan that reinforces the relevance of the customer can be seen in many places, for example on the employees' clothing. The employees wear badges which make clear which targets are relevant to

satisfy the customer. Examples are quality, reliability of delivery and cost. There are specific targets for groups in various departments too, although they are not communicated by badges. The relevance of all this is repeated every morning in the group meeting where the performance of the previous day is also presented. Large displays on the workfloor also show these results, but they also show individual results, including late arrivals and absence (including the reasons). In case of repeated mistakes, re-education of employees is considered, rather than blaming the one who made the mistakes. A bsenteeism in both facilities is lower than the national average, although this may be due to the fact that it is a relatively young facility in all respects.

A nalysis of the lean production case shows that the customer focus is assured through badges, meetings and targets. It is made clear repeatedly what should be done to satisfy the customer. Throughout the case, there is a clear process focus. There are no clear job descriptions, but very clear descriptions of operational tasks. A Iso, targets are always linked to processes. The same applies for skills. There is an immediate link betw een the skills that are recognized by the organization and the execution of tasks. General education is not emphasized. Training for skills is important. The process should always run smoothly, solution of problems in cases of absenteeism are ignored, in a way: the group simply should put in some more effort. Group pressure is instrumental to use the SOPs. Continuous improvement is achieved through ever better standardized operational procedures. It may be concluded that operational autonomy ever increases with the development of procedures.

\section{A nalysis and conclusions}

A t present the author does not want to join the discussion about the differences between reflective and lean production (e.g. [2,4]). Here the similarity that both approaches lead to "operational autonomy" is stressed. There are even similarities in the way the two approaches achieve operational autonomy. Both approaches have a strong focus on the operational process, they build up the organization on the basis of the process in the organization. A Iso, both approaches use teams or work groups to achieve operational autonomy. In both approaches these groups provide group pressure that stimulates performance, although only in the lean approach was this a consciously designed situation. The pressure of the group and the responsibilities that come with "operational autonomy" can be stressful in both approaches. Both approaches underline the importance of the operational skills of the members of the work groups. 
IJOPM 16,2

180
The big difference is in the way in which the operational process is arranged. Within lean production, operational autonomy is secured through a set of SOPs. At the beginning, such SOPs are present only to a limited degree and operational autonomy is limited. How ever, as time proceeds, there are more and more SOPs which enable the group to determine how to work in a great many situations. A s SOPs are based on actual operational problems, designed by supervisors, and discussed with operators before introduction, the SOPs are actually used. The SOP-establishing procedure makes it relatively easy to keep a match between the operational process in the group and the requirements of the organization. A s the supervisor knows the organizational goals. A lso, the SOPs make training of new operators relatively easy. Newly established routines can be transferred easily to other work groups.

In reflective production, on the other hand, more is left in the hands of the group. The group learns to understand how decisions should be made and has decision-making capabilities. So, learning does not primarily take place by establishing procedures, but through ever increasing skills of operators to perform tasks and to solve problems. Through the learning, a situation of operational autonomy is gradually achieved. The way of working makes it difficult to transfer newly developed procedures from one group to another, as every group has to decide on its own how it will work exactly. Furthermore, it is a time-consuming process to teach these decision-making skills to new members of the work groups.

Both approaches have their own problems in the start-up phase. When the lean approach is followed, it will be difficult to start without any SOPs. In the reflective approach, it will be difficult to start with a group that has not yet devel oped capabilities to cope with all situations. How ever, after this start-up situation, both approaches will result in "operational autonomy".

Is one of the two approaches the best? It is possible to construct a proposition on the basis of Galbraith's "designing complex organisations"[21]. From his work it can be concluded that the degree to which an organization is capable of co-ordinating activities through rules, programmes, hierarchy and goal-setting depends on the frequency of disturbances and the degree to which the hierarchy is capable of coping with the problems involved. One of the approaches that can be followed when rules, hierarchy and goals do not solve the problems involved is the introduction of autonomous tasks.

On the basis of this, the proposition is: In case of relatively large uncertainty in the operational conditions and in case of little repetition in the production, only the reflective approach results in "operational autonomy". Under such conditions, it would be impossible to establish a set of SOPs that covers all situations. In more repetitive situations, with fewer exceptions, also the lean approach results in operational autonomy. In a situation where the lean approach is possible it will be more efficient than the reflective approach.

Galbraith did not specifically pay attention to the effects of his design Lparameters on the process. It is clear that operational autonomy of the approaches in his work such as lateral linkages and hierarchy will lead to 
involvement of others in the organization in the operational process. A s a consequence, such approaches are not useful to design an organization with "operational autonomy". However, vertical information systems and slack do not disturb the autonomy of the processes and can be of use in both the autonomy reflective and the lean approach. A s made clear in the case studies, coordination by goals is used in both approaches.

In cases where only the reflective approach is possible, organizational learning depends on learning of individuals at the group level to master different situations. The work will be challenging on the one hand, as it is diverse and it has a certain degree of uncertainty. On the other hand, the work is stressful, as the groups and the individuals in the groups carry crucial responsibilities.

In cases where the lean approach is followed, rules can relatively easily be transferred to new operators or other groups of operators. A lso, less reflective skills are required of the operators in this situation in comparison with the operators in the facility designed in line with the reflective approach. A s a result, in such situations it is likely that the lean approach will be more efficient than the reflective approach, although it is possible to use the latter instead of the first. Organizational learning lies in the establishment of better SOPs in the lean situation. Working in groups is less uncertain compared with group work in the reflective situation, but also less challenging. So, the jobs are different. In both situations the use of multi-skilled personnel is a necessity, but the reflective design calls for a number of skills which are not needed within the lean design.

The likelihood of the proposition is underlined by the reflective case. In that case, the explicit aim was to keep the work groups autonomous in their task policies. In reality a certain degree of standardization of working procedures took place, as explained before. This can be explained by the fact there was a considerable degree of repetition in the tasks of the work groups. A Ithough this case has had worldwide recognition as being the finest example of the approach, less repetitive production with more exceptions is needed to show the value of the approach completely. Oddly enough, such a facility exists within Volvo, but hardly got attention within the literature. It is a site where customized cars such as police cars are assembled. Other less repetitive cases of group work that we studied also showed that operational autonomy relied on the decentralized, autonomous task policies by the group, which is in line with the proposition.

\section{Note and references}

1. Womack, J.P., Jones, D.T. and Roos, D., The M achine that Changed the World, Rawson A ssociates, New York, NY, 1990.

2. A dler, P.S. and Cole, R.E., "Designed for learning: a tale of two autoplants", Sloan Management Review, Spring 1993, pp. 85-94.

3. Ellegård, K., Engström, T., Johansson, B., Johansson, M., Jonsson, D. and M edbo, L., "Reflective production in the final assembly of motor vehicles - an emerging Swedish challenge", International Journal of Operations \& Production Management, Vol. 12 No. $7 / 8,1992$. 
IJOPM
16,2

182
4. Berggren, C., “Nummi vs. Uddevalla”, Sloan M anagement Review, W inter 1994.

5. Benders, J. and de L eede, J., "K aizen in T he Netherlands; evidence from a case study", paper presented at the 2nd International Euroma Conference on Management and $\mathrm{New}$ Production Systems, University of Twente, Enschede, 1995.

6. Y in, R.K., Case Study Research: Design and M ethods, Sage, Beverly Hills, CA, 1984.

7. Trist, E.L. and Bamforth, K.W., "Some social and psychological consequences of the Longwall method of coal getting", Human Relations, Vol. 3, 1951, p. 38.

8. Herbst, P.G., A utonomous Groups Functioning: An Exploration and Behaviour Theory and M easurement, Tavistock, London, 1962.

9. Cherns, A., "Principles of sociotechnical design revisited", Human Relations, Vol. 40 No. 3, 1987.

10. de Sitter, L.U. et al., Het flexible bedrijf, Kluwer, Deventer, 1986.

11. Kuipers, H., "Zelforganisatie als ontwerpprincipe, sociotechnisch organisatieontwerp in vijftien stellingen", Gedrag en Organisatie, Vol. 2 No. 4/5, 1989 (in Dutch).

12. Kuipers, H. and van A melsvoort, P., Slagvaardig Organiseren, Inleiding in de sociotechniek als Integrale Ontwerpleer, Kluwer, Deventer, 1990 (in Dutch).

13. Morgan, G., Images of Organization, Sage, Beverly Hills, CA, 1986.

14. Emery, F.E., "The next thirty years: concepts, methods and anticipation", Human Relations, No. 20, 1967.

15. A shby, W.R., Design for a Brain, John Wiley \& Sons, New York, NY, 1952.

16. Herbst, P.G., Sociotechnical Design, Tavistock, London, 1974.

17. A rgyris, C. and Schon, D.A., Organizational Learning: A T heory of A ction Perspective, A ddison-Wesley, Reading, MA, 1978.

18. van Eijnatten, F.M., "The paradigm that changed the workplace", Social Science for Social A ction: Toward Organizational Renewal, Vol. 4, The Swedish Center for Working life, Stockholm, 1993.

19. Janis, I.L., V ictims of Groupthink, Houghton-M ifflin, Boston, MA, 1972.

20. Womack, J.P. and Jones, D.T., "F rom lean production to the lean enterprise", Harvard Business Review, March-A pril 1994, pp. 93-103.

21. Galbraith, J., Designing Complex Organisations, A ddison-Wesley, Reading, M A , 1973. 
1. MaJie, Jie Ma, JiaoFeng, Feng Jiao, LauChi Keung, Chi Keung Lau, LinZhibin, Zhibin Lin. 2018. The relationships between shop floor management and QCCs to support Kaizen. International Journal of Quality \& Reliability Management 35:9, 1941-1955. [Abstract] [Full Text] [PDF]

2. Algan Tezel, Lauri Koskela, Zeeshan Aziz. 2018. Lean thinking in the highways construction sector: motivation, implementation and barriers. Production Planning \& Control 29:3, 247-269. [Crossref]

3. Adriana F. Araújo, Maria L. R. Varela, Marivan S. Gomes, Raissa C. C. Barreto, Justyna Trojanowska. Development of an Intelligent and Automated System for Lean Industrial Production, Adding Maximum Productivity and Efficiency in the Production Process 131-140. [Crossref]

4. Ivo Domingues, José Cunha Machado. Lean Thinking in Non-profit Organizations 71-107. [Crossref]

5. Rodrigo Valio Dominguez Gonzalez, Manoel Fernando Martins. 2015. Gestão do conhecimento: uma análise baseada em fatores contextuais da organização. Production 25:4, 834-850. [Crossref]

6. Sarah-Jane Cullinane, Janine Bosak, Patrick C. Flood, Evangelia Demerouti. 2014. Job design under lean manufacturing and the quality of working life: a job demands and resources perspective. The International Journal of Human Resource Management 25:21, 2996-3015. [Crossref]

7. Rodrigo Valio Dominguez Gonzalez, Manoel Fernando Martins. 2014. Mapping the organizational factors that support knowledge management in the Brazilian automotive industry. Journal of Knowledge Management 18:1, 152-176. [Abstract] [Full Text] [PDF]

8. Mandar Dabhilkar, Pär Åhlström. 2013. Converging production models: the STS versus lean production debate revisited. International Journal of Operations \& Production Management 33:8, 1019-1039. [Abstract] [Full Text] [PDF]

9. José Moyano-Fuentes, Macarena Sacristán-Díaz. 2012. Learning on lean: a review of thinking and research. International Journal of Operations \& Production Management 32:5, 551-582. [Abstract] [Full Text] [PDF]

10. Macarena López-Fernández, Gonzalo Sánchez-Gardey. 2010. Managing the effects of diversity on social capital. Equality, Diversity and Inclusion: An International Journal 29:5, 491-516. [Abstract] [Full Text] [PDF]

11. Alberto Bayo-Moriones, Alejandro Bello-Pintado, Javier Merino-Díaz-de-Cerio. 2010. The effects of integrated manufacturing on job characteristics. New Technology, Work and Employment 25:1, 63-79. [Crossref]

12. Juan A. Marin-Garcia, Manuela Pardo-del-Val, Tomas Bonavia. 2008. Análisis de programas de mejora continua. Un estudio longitudinal en una empresa industrial. Gestão \& Produção 15:3, 433-447. [Crossref]

13. Jordi Olivella, Lluís Cuatrecasas, Nestor Gavilan. 2008. Work organisation practices for lean production. Journal of Manufacturing Technology Management 19:7, 798-811. [Abstract] [Full Text] [PDF]

14. Ian Greenwood, Hanne Randle. 2007. Team-working, Restructuring and Skills in UK and Sweden. European Journal of Industrial Relations 13:3, 361-377. [Crossref]

15. Ngai Kheong Ng, Jianxin Jiao. 2004. A domain-based reference model for the conceptualization of factory loading allocation problems in multi-site manufacturing supply chains. Technovation 24:8, 631-642. [Crossref]

16. Moacir Godinho Filho, Flavio César Faria Fernandes. 2004. Manufatura Enxuta: uma revisão que classifica e analisa os trabalhos apontando perspectivas de pesquisas futuras. Gestão \& Produção 11:1, 1-19. [Crossref]

17. Anne Sey. 2000. Team Work in Japan: Revolution, Evolution or No Change at All?. Economic and Industrial Democracy 21:4, 475-503. [Crossref]

18. Phil Johnson, Joanne Duberley, Paul Close, Cathy Cassell. 1999. Negotiating field roles in manufacturing management research. International Journal of Operations \& Production Management 19:12, 1234-1253. [Abstract] [Full Text] [PDF]

19. Moreno Muffatto. 1999. Evolution of production paradigms: the Toyota and Volvo cases. Integrated Manufacturing Systems 10:1, 15-25. [Abstract] [Full Text] [PDF]

20. Emilio Bartezzaghi. 1999. The evolution of production models: is a new paradigm emerging?. International Journal of Operations \& Production Management 19:2, 229-250. [Abstract] [Full Text] [PDF]

21. Gianluca Spina. 1998. Manufacturing paradigms versus strategic approaches: a misleading contrast. International Journal of Operations \& Production Management 18:8, 684-709. [Abstract] [Full Text] [PDF]

22. Ivor J. Parry, David Tranfield, Stuart Smith, Morris Foster, Sarah Wilson. 1998. Reconfiguring your organisation: a teamwork approach. Team Performance Management: An International Journal 4:4, 166-176. [Abstract] [Full Text] [PDF] 